\title{
Responding to the Literacy Challenge Amidst its Resource-hungry Realities: The case of Southern Mindanao, Philippines
}

\author{
Fraulein Agcambot OCLARIT \\ Chief Librarian, Valdez Mother and Child (VMC) City College, Inc. \\ Tacurong City, Philippines \\ Ivan Limbungan ORTUOSTE \\ Faculty, College of Liberal Arts \\ Notre Dame of Marbel University \\ City of Koronadal, South Cotabato \\ Philippines
}

\begin{abstract}
Addressing the challenge of literacy is formidable for countries faced with chronic problems on finance. In Southern Mindanao, one of the most culturally diverse regions in the Philippines, scores of public schoolchildren remain with very limited access to libraries and other information infrastructures. Textbook ratio lies steadily between 1:3 to 1:7. Despite its resource-hungry realities, there are laudable moves by the local Departments of Education to boldly initiate development intervention programs at the level of the grassroots to combat the problem of illiteracy. The Province of Sultan Kudarat has the Drop Everything And Read (DEAR) and the Reading - At Reader's Reach (REARER) Programs while South Cotabato boasts of its School and Home Advocacy Reading Program (SHARP), and the Education Summit it recently convened. These initiatives showcase the "bayanihan" spirit wherein Filipinos collectively contribute towards narrowing the local-level divide that separates those with access to technology, information and information infrastructures in the mainstream from those in far-flung portions of Southern Mindanao.
\end{abstract}

\section{The Context}

In a movingly bold and honest speech before Philippine educators at the 2004 National Educators Congress, incoming Department Secretary Florencio "Butch" Abad openly admitted to a crisis in Philippine education and went on to cite the following to support such contention:

In the 2004 government-initiated High School Readiness Test administered to pupils graduating from basic education, only eight thousand out of 1.2 million examinees (or $0.64 \%$ ) scored $75 \%$ or better. Using a passing mark of $50 \%$ percent (proportion of questions with correct answers), barely 18\% passed the competency levels for English; 8\% passed for Mathematics and 10\% for Science. 
Ten thousand out of fifty-one thousand teachers who took the SelfAssessment Test for English scored $75 \%$ or better. This translates to about $81 \%$ of Filipino teachers with inadequate proficiency in the English language. (Abad 2004)

The scenario at the international scene is pretty much the same. Filipino schoolchildren placed fifth to the last in Mathematics and fourth to the bottom in Science in the recently-concluded Trends in International Mathematics and Science Study (TIMMS) administered to some five hundred thousand students across forty-five countries in 2003. These figures failed to reverse the equally-dismal results of the 1995 TIMMS and the 1999 TIMMS-Repeat (“TIMMS 2003 Results,” n.d.)

These are only a few of the more glaring and disturbing statistical truths that attest to the progressively dwindling academic performances of Filipino schoolchildren. It is sad to note that these realities have to come at a time when the country is supposed to be breeding generations of individuals who are well-equipped for their increasinglycomplex future, and propagating a culture of love for learning in consonance with the demands of the information-driven times. How ironic for certain Philippine realities to remain contradictory to what this Information Age demands of its children. This brings one to ask whether the culture of love for learning drowned with the deluge of information in the mainstream.

Abad (1994) lamented on poor fiscal allocation as the perennial culprit but he said that it is not the sole contributory factor to this dismal state of Philippine education. One other issue of that of the huge student population of over nineteen (19) million -- or more than four times the entire population of Singapore, New Zealand and Brunei Darrusalam. Abad stressed that while it may be sad that resources are just not enough, this is a reality that Filipinos have to admit, collectively contend with and address. The current situation, dismal as it may seem, is not at all that hopeless.

\section{The Problem}

\section{Glaring Absence of Libraries in the Age of Information}

Among the most glaring casualties of poor fiscal allocation is the library which has, for a very long time now, failed to compete for prioritization in the budget pie with the other school infrastructures. Most of the publicly funded institutions providing basic education in the country remain without this very basic provision. It is, therefore, no longer surprising to see generation after generation of Filipino public schoolchildren graduating from elementary education with very limited and at the worst case nil experience with libraries and later find themselves navigating less-equipped the increasingly information-driven mainstream. This, naturally, diminishes their chances of competing with their more privileged counterparts.

It is widely acknowledged that education is not a turf exclusive to teachers and that librarians have as much stake and influence to the intellectual growth of children as their educator-counterparts. Filipino librarians, however, are still statistically too few and politically not strong enough to lobby for much needed attention, especially as regards the issue on the absence of libraries in public schools. Sometimes, it makes little sense advocating literacy through libraries with all the other school infrastructures competing with an overburdened and problematic fiscal resource base. Due to these cultural and fiscal impediments, and to the poor positioning of librarians in influencing policy advocacies, the issue on public elementary school libraries and public libraries 
has clearly been relegated to the sides. Whether to have a library within a school or community setting becomes more a matter of political will on the part of the stakeholders within a given community. It is worth mentioning that despite these limitations, there are isolated best practices in the provinces that showcase how some schools managed to put up libraries of their own out of sheer political will and an appreciation for the role libraries play in the optimum development of children.

Poor and Slow Implementation of R.A. No. 7743

Republic Act No. 7743, a very important national mandate which stipulates for the establishment of congressional, provincial and municipal libraries and barangay centers all over the country, has, to date, only been partially implemented. Twelve years since its implementation in 1993, barely $62 \%$ of the seventy-nine (79) provinces, $35 \%$ of the one thousand four hundred ninety-nine $(1,499)$ and $.8 \%$ of the forty one thousand nine hundred sixty-nine $(41,969)$ barangays have implemented the mandate. (Data culled from The National Library, Public Libraries Division).

Table 1

Extent of R.A. 7743 Implementation

\begin{tabular}{|l|r|}
\hline No. of Provinces & 79 \\
\hline No. of Provincial Libraries & 49 \\
\hline & \\
\hline No. of Municipalities & 1499 \\
\hline No. of Municipal Libraries & 527 \\
\hline & \\
\hline No. of Barangays & 41969 \\
\hline No. of Barangay Reading Centers & 373 \\
\hline
\end{tabular}

\section{Charting the Future of Filipino Children: National-Level Initiatives}

\section{Earlier Attempts at Intervention}

A review of the literature on documents that chart the welfare and education of the Filipino children indicates that there is a consensus among stakeholders that the future of the Filipino children are as fragile as these children are, hence, it needs to be confronted with immediacy and a clear sense of social responsibility if only to guarantee them a life of quality and dignity that would justify their existence.

Documents drawn from collaborative consultations at the national level to this end are a plenty. For instance, in 1991, the Council for the Welfare of Children came up with The Filipino Children: 2000 and Beyond: Philippine Plan of Action for Children. Also noteworthy of mention is the Education and Manpower Development Programs, volume 1: Areas of Concern in Philippine Education, published by the Congressional Commission on Education in 1993.

In 1995, the then Department of Education, Culture and Sports (DECS) published the Masterplan for Basic Education (1996-2005): Modernizing Philippine Education. 
In 1998, UNICEF commissioned a prospective study with a research framework that takes off with a vision of what the Filipino child would be as adult in 2020. The rationale was that the "children pay the highest price for our shortsighted policies and programs but they will certainly be the beneficiaries of whatever investments we now make for their future" ("Megatrends," 1998, p. 23) .The survival of the Filipino child naturally hinges on a plethora of appropriate policies and programs.

Megatends: The Future of Filipino Children is a landmark publication that envisions the Filipino Adult of 2020 as possessing the desired values of "spirituality and moral uprightness; thinking, creative and articulate...active in community life and nation-building and possessing a global outlook." Said values are to be backed up by the desired qualities of institutions in the year 2020 as outlined in the Table that follows: (p. 24)

Table 2

Vision of the Filipino Adult and Quality of Institutions of 2020

\begin{tabular}{|c|c|}
\hline $\begin{array}{l}\text { A Vision for the Filipino Adult } \\
\text { In the Year } 2020\end{array}$ & $\begin{array}{l}\text { Qualities of Institutions in } 2020 \\
\text { That would support the Vision }\end{array}$ \\
\hline $\begin{array}{l}\text { - at home with one's cultural identity } \\
\text { - imbued with spirituality and moral } \\
\text { uprightness } \\
\text { enterprising, competitive and } \\
\text { cooperative } \\
\text { - thinking, creative and articulate } \\
\text { - caring, sharing and nurturing } \\
\text { - has a global outlook } \\
\text { - independent/autonomous in thinking } \\
\text { and outlook } \\
\text { - economically self-sufficient } \\
\text { active in community life and nation- } \\
\text { building } \\
\text { - well-balanced individual } \\
\text { self-reliant }\end{array}$ & 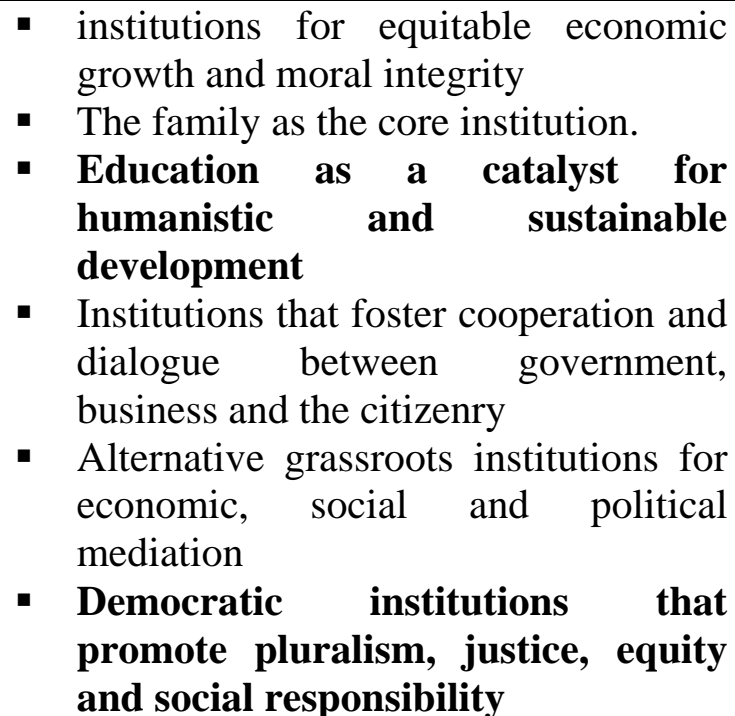 \\
\hline
\end{tabular}

A number of other documents with similar concerns have since been written, for instance, the Medium-Term Philippine Development Plan of 2001-2004 which looks at investing in human capital through education and training as supporting economic growth and breaking the cycle of poverty from one generation to the next. No less than the Philippine Constitution acknowledges this government responsibility of providing equal opportunities for everyone to develop their human capacities. It acknowledges that investments in education is beneficial to society and contributes, albeit indirectly, to the community as well. (National Economic and Development Authority, 2005).

All of these attempts at early intervention via policies indicate that there is actually no failure on the part of the Philippine government and its major stakeholders to look into the welfare of its own children. It is, however, one thing to simply chart the future. Translating all these to more concrete and meaningful terms that would be beneficial to children remains the country's biggest challenge. The problem of implementation has a lot to do with finances and given the huge budgetary problem that 
the country faces, such a task becomes too daunting to undertake - one that requires very strong political will and determination, and intensified collaboration of stakeholders over and above fiscal support.

It is too much of a simplification to say that there have not been changes since, but it is fair enough to say that unfortunately, most of these changes hardly managed to touch on the essence of things, especially on issues as regards access to libraries, information and information infrastructures for the public schoolchildren and the marginalized cultural minorities in the country, particularly those in the countryside like Southern Mindanao. And sad but true, the threat of the gap between the information haves and have nots becoming too wide lurks, endangering the future of a great majority of these children.

In the Philippines, it is hard to imagine why there are hardly any indications that the establishment of public and school libraries, which are an important components for learning, and for cultivating a culture of love for learning amongst children, is in the priority agenda of the government despite a national mandate and even as UNESCO's current battle cry of “Information for All” is too loud not to be heard and too conspicuous to miss. It is quite incomprehensible that libraries hardly figure in the scene, even when the greatest challenge of the present times is that of addressing the issue of social inclusion where every individual participates in the march towards the Information Society. Realities would attest that this noble vision of social inclusion remains elusive still, especially for the marginalized minorities of Southern Mindanao as well as for scores of its populace who are far from the mainstream. And although much has already been gained from past and current global, national and locallevel initiatives, still much remains wanting to be done. What is more important for now is to safeguard the gains from these initiatives by assuring sustainability, periodically monitoring and reviewing their impacts, and for the vision of "Information for All" to be taken literally as UNESCO has intended it to be.

\section{Southern Mindanao, Philippines: Making Do With What is at Hand in the Land of Promise}

\section{Profile of A Country}

The Philippines is a republic in the western Pacific Ocean, bounded on the east by the Philippine Sea and the Pacific Ocean. On its south is the Celebes Sea, and on the west is the South China Sea. The country is tropical and has a current estimated population of about 86 million. It comprises 7,100 islands; the second largest of which is Mindanao located in the southernmost part of the country 


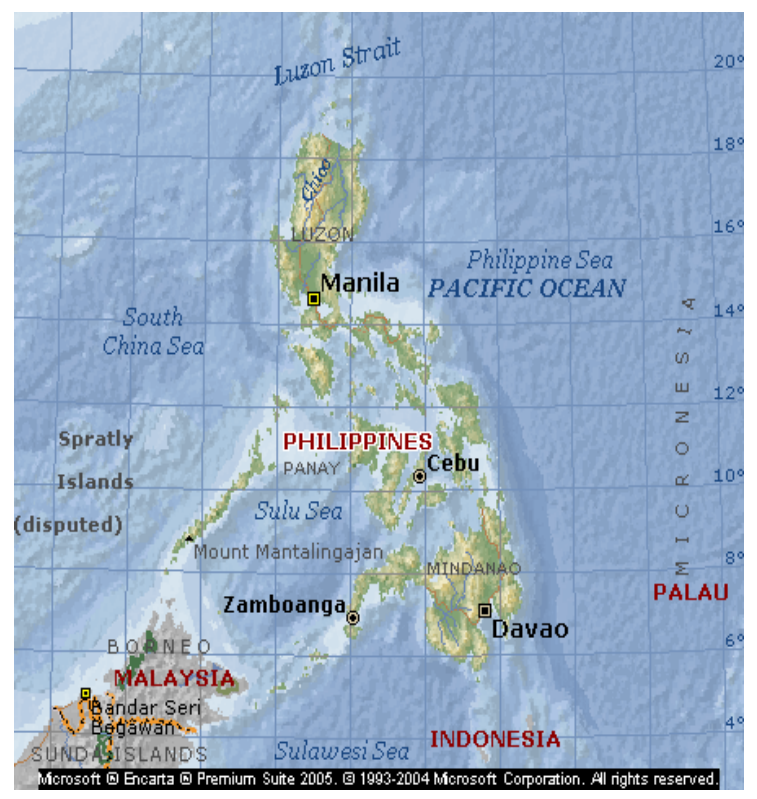

Map of the Philippines

Figure 1

\section{The Land of Promise}

Mindanao, once touted as the "Land of Promise" hosts most of the Philippine Muslim population, Christian settlers from central and northern Philippines, and scores of indigenous communities, making it one of the most culturally-diverse regions of the country. Mindanao also politically includes the 400-island Sulu Archipelago, which extends from the tip of the Zamboanga peninsula

The focus of this study is two provinces of Southern Mindanao, specifically the provinces of Sultan Kudarat and South Cotabato as highlighted in the figure that follows:

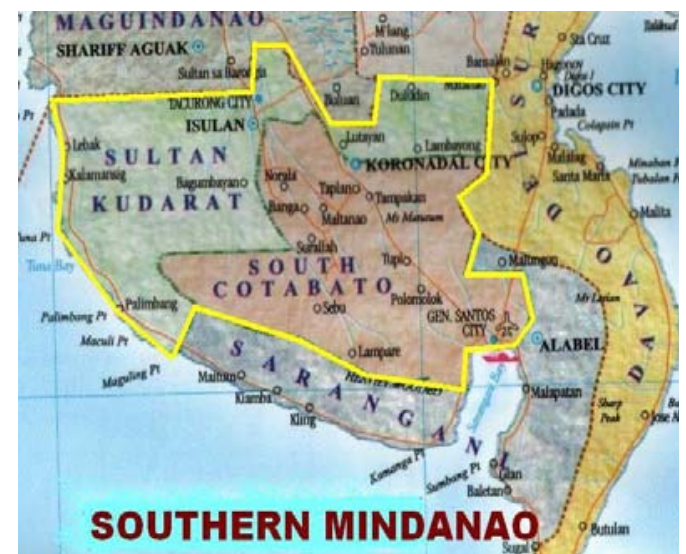

Map of Southern Mindanao

Figure 2 


\section{Sultan Kudarat}

Named after the most famous and perhaps the greatest ruler to rise among the Maguindanaoans, Sultan Mohammed Dipatuan Kudarat, the Province of Sultan Kudarat is bounded on the north by North Cotabato and Maguindanao, on the east by Davao del Sur, on the West by the Moro Gulf and on the South by South Cotabato.

The Province of Sultan Kudarat has one city, which is Tacurong, eleven (11) municipalities, three of which are coastal, and two hundred forty-nine (249) barangays. . It is home to both Christian migrants who now outnumber Muslims and highlanders.

\section{- Access to School Libraries of Sultan Kudarat Public Schoolchildren}

Currently, there are about ninety three thousand one hundred forty-eight $(93,148)$ pupils enrolled in three hundred twenty-one (321) publicly funded institutions providing elementary education. Of these, there are only about thirty one (31) libraries attached to the Learning Resource Centers of the Districts in the province. The libraries are in varying degrees of condition, ranging from highly functional to merely storehouses of textbooks of superseded editions. All of the libraries are manned by teacher-designates who are not librarians by profession.

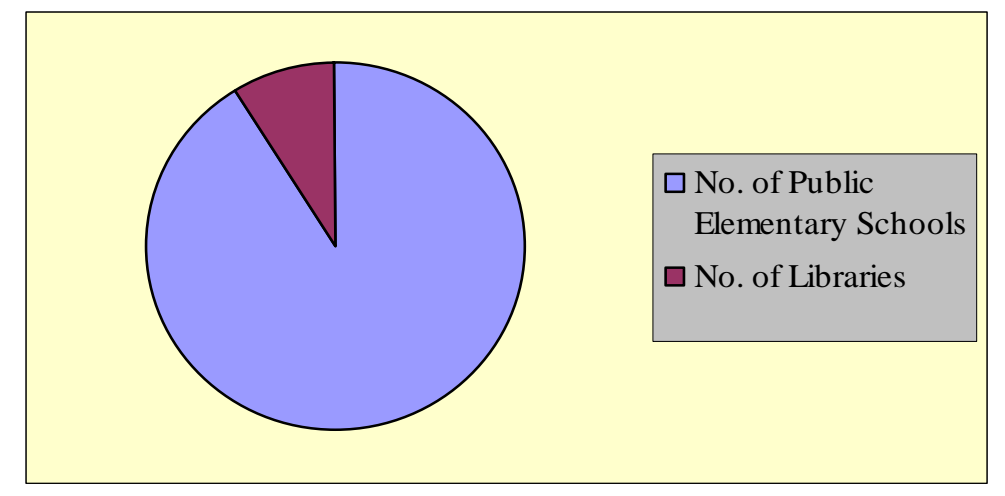

No. of Libraries to No. of Public Elementary Schools in Sultan Kudarat

Figure 3

\section{- Access to Public Libraries}

Sultan Kudarat, like any other province in the country, has partially implemented R.A. 7743. Currently, there is one highly functional provincial library, and only four out of its eleven municipalities have functional municipal libraries. 


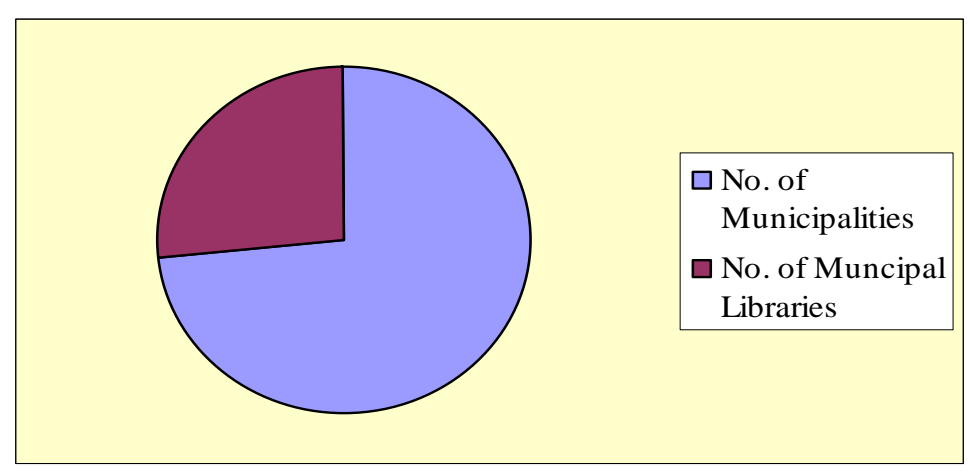

No. of Municipal Libraries to No. Municipalities in Sultan Kudarat Province

Figure 4

\section{- Local-level Literacy Initiatives in Sultan Kudarat}

Not to be dismayed by these realities and the chronic problem with the budget, the Department of Education, Division of Sultan Kudarat, through the initiative of Mr. Gerardo Magno, Division English Coordinator, launched the program DEAR (Drop Everything and Read): An Invitation to Reading and Love of Reading that aims at "catching the non-readers before they fall." It hopes to provide every reading educator the appropriate knowledge, skills and attitudes in the assessment of every Sultan Kudarat child in terms of reading and comprehension skills.

"DEAR" takes off with a vision of a reading, learning, thinking and relating division. It basically is an observance of a ten to thirty minute reading time where everyone is enjoined to drop everything and take hold of any reading material that suits one's interest. It is not space-bound as every place the reader finds conducive is a learning place. It is both an invitation and a motivation to model reading hoping to infect another one to find joy and meaning in the activity. It hopes to make reading a habit down to the last Sultan Kudarat Child.

The Reading - At Reader's Reach (REARER) Program is another program which showcases the Division's banner in reading education. "REARER" hopes to open the way to reading literacy.

The mission is to bring reading closer to the hearts of non-readers. It is about getting closer to a child's heart and knowing how and when help is to be extended. It acknowledges that it is the teacher's serious task as facilitator of learning to promote the "REARER" Program.

It advocates for sustaining the spirit of concern, perseverance, and patience. Coupled with dedication and commitment, it endeavors and dreams to carve in the hearts of every Sultan Kudarat pupil/student the love of reading, and on the part of the teachers as reading educators, the love and passion to have the non-readers read. The greater vision is to bring reading education within the reach of the reader.

\section{South Cotabato}

South Cotabato is located in the southmost part of the Island of Mindanao. It is bounded in the North and West by the Province of Sultan Kudarat, in the east by the 
province of Davao del Sur and in the South by Celebes Sea. Sarangani Bay is South Cotabato's main access point where part of General Santos City is also located.

South Cotabato is home to most of the non-Muslim indigenous peoples (IPs)., or lumads. The Municipalities of Lake Sebu, T'boli and Tampakan are where most of the IPs are currently concentrated.

\section{- Access to School Libraries of South Cotabato Public Schoolchildren}

The combined student population of Koronadal City Schools and the other schools in South Cotabato is currently at one hundred ten thousand for hundred eightysix.(110,486) distributed across three hundred nine (309) public elementary schools. There are roughly thirty one (31) libraries attached to the Learning Resource Centers in all the districts of South Cotabato. As in the Division of Sultan Kudarat, the libraries are concentrated in the mainstream, which places scores of public schoolchildren at a disadvantage as far as accessing information is concerned.

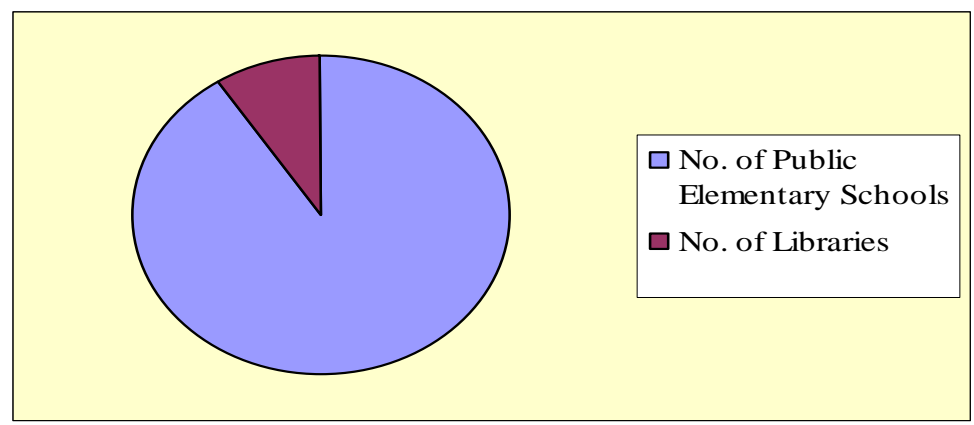

No. of Libraries to No. of Public Elementary Schools in Koronadal and South Cotabato

\section{- Access to Public Libraries}

Figure 5

The picture as regards access to public libraries in the Province South Cotabato is the same as that in Sultan Kudarat. Four of its eleven municipalities have municipal libraies. There is also a functional provincial library.

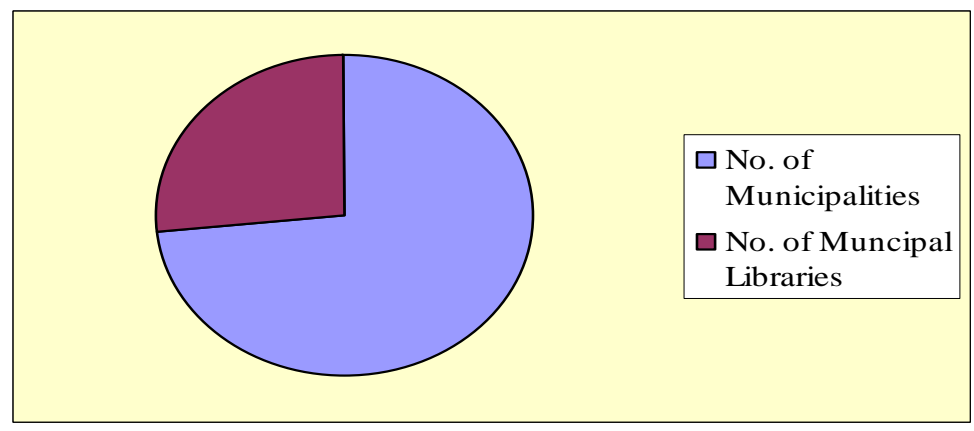

No. of Municipal Libraries to No. Municipalities in South Cotabato Province Figure 6 


\section{- Local-level Literacy Initiatives in South Cotabato}

The Division of South Cotabato "continues to fight illiteracy despite the difficulties that recur endlessly” (Golez, 2004, p. 1). It remains active in supporting the nation-wide program E-CARP (or Every Child A Reader Program) of the Department of Education.

Among the laudable programs unique to South Cotabato is the School and Home Advocacy Reading Program (or SHARP) which is currently in its infancy stage. This program which was initiated by Mrs. Felicitas Jabido, Division English Coordinator, advocates for a regular daily Family Joy Reading Time (FJRT) wherein a reader of the family helps or assists a non-reader in his schoolwork. It supports the idea that literacy takes its roots in the home which is the child's first school and that the education of the child should be a partnership between the parents and the school.

The Adopt-A-School Program is another program that showcases Filipino ingenuity in rising above his present conditions. It is supported by Dole Philippines Tropi Fresh and Stanfilco with Mahintana Foundation. The program provides trainings for teachers and donates solicited books to schools.

Worthy of mention since it is the first of its kind in the country is the Education Summit which the Provincial Local Government Unit (LGU) of the Province of South Cotabato, through the initiative of Sangguniang Panlalawigan Board Member Rene Jumilla, Chair of the Education Committee, convened with participants coming from the different sectors of society. Said undertaking assessed the State of Education in South Cotabato, enumerated the problem areas and drew realistic solutions to the more pressing concerns relating to the education of the children and youth of South Cotabato. It culminated with the drafting of the Statements of Commitment from these sectors to collectively address local-level concerns.

\section{Local Library Associations Making Worthy Contributions}

The SOCCSKSARGEN Librarians Association, Inc. (SOCOLA), one of the few active local associations for librarians with membership coming from both provinces have contributed immensely to the advancement of local librarians through the trainings and workshops they organize from time to time to upgrade the skills and capabilities of local librarians. It provides a venue for dialogue among local librarians to address homegrown problems on matters pertaining to information utilization, organization and management.

Recently, the Philippine Librarians Association, Inc. (PLAI) organized regional PLAIs to bring the only association of licensed librarians in the Philippines closer to the provinces. The South Central Mindanao Librarians Association (PLAI XII) elected its Interim set of officers just recently. The organization hopes to complement the activities of SOCOLA.

The picture that can be gleaned from both provinces as far as access to public school libraries and public libraries is dismal considering that the number of affected children is high at two hundred three thousand six hundred thirty-four $(203,634)$, and around a third of whom are cultural minorities.

However, it is also clear from the aforementioned that there have been initiatives undertaken by both provinces to make full use of the only of the only resource they are abundant with -- their human resource to coalesce in order to elevate the level of quality education for Southern Mindanaoan children. Local associations of 
librarians are in place, and while there is still no escaping the reality we are still lagging too far behind, and are still not moving as fast as our neighbors are moving in the region, there is movement, no matter how slow. Crucial steps have been taken and are being taken still.

\section{The Challenge}

\section{Quality Education for Southern Mindanaoan Children}

Taking seriously UNICEF's definition of childhood that focuses on state, condition and quality of the years between birth and the attainment of adulthood, it becomes even more urgent to rise above current conditions, for in essence, what this definition means is that the burden lies heavy on our shoulders for we are co-creators of the adults these children will eventually become, and that their future relies on how much we have invested to guarantee them a quality of education they rightfully deserve. Developmental interventions are moral and social obligations, especially because the schoolchildren of today are in midst of the best and the worst of times. With the advances courtesy of technology, their present world possesses powers and perspectives inconceivable many years back. Yet, the world of today is also faced with a legion of problems ranging from emerging demands for survival skills necessary as the rest of the world metamorphoses into an information society. Technology also spawned emerging concepts of literacy and so what used to be enough no longer holds true. Because of the deluge of information, "what used to count as effective knowledge no longer is adequate for there are now concepts like computer literacy, civic literacy, global literacy and cultural literacy.” (“Information Literacy,” 1989, p. 97)

Today's environment is, indubitably, information-intensive, and information literacy is a survival skill. This creates an increasingly-fragmented information base, marking a frontier so clearly defined that it divides humanity into two totally different groups. On one side of the divide is a huge mass of underprivileged in terms of accessing information, which is a vital requisite to surviving the demands of the present times. These are developing countries like the Philippines constrained primarily by chronic lack of finance, poor information resources and lack of possibilities for needed continuous upgrading of professional knowledge and skills. The information haves at the other extreme continue without restraint metamorphosing into an Information Society.

The importance of providing access to libraries, information and information infrastructures to children is so well-captured in this philosophy drawn from a document written two decades back:

Today's schoolchildren will one day be responsible for creating the nation's wealth and organizing its society...It is widely acknowledged that they must know how to learn. A central feature of the learning process is learning to deal with information...[which] exists in increasing quantity and comes from a variety of sources through an ever-increasing range of media. An ability to cope with this changed circumstances is not innate. It must be acquired (Office of Arts and Libraries, 1984, p. 1) 


\section{The Solution}

\section{Increased Access to Information}

What if wired technology may not be the best answer yet? Such statement is one that is practical to ask given countryside Philippine realities. For, indeed, what if in the far-flung portions of Mindanao, to dream of wired technology or of connectivity may be dreaming too far still? In this increasingly information-driven environment, it is fitting to assess the implications of the present-state-of-global-affairs in the context of certain realities in portions of Southern Mindanao, Philippines, where equity of access to information remains akin to an elusive dream for most the children. Indeed, it is worth acknowledging that "in a world which is simultaneously coming together as a global society, while it splinters apart into even smaller ethnically defined pieces, the two-faced potential of literacy to both open and bar doors of opportunity becomes increasingly evident” (Hornberger, 1997, p. 3)

A trip to the municipalities of Lake Sebu, and T’boli South Cotabato, for instance, reveals a number of realities that are too glaring to miss. There are no public libraries in both municipalities that currently host communities dominated by the indigenous peoples (IPs), the T'bolis and B'laans. Less than ten percent of their public schools have functional libraries and textbooks are wanting. For these two municipalities, the importance of these public provisions cannot be taken for granted because most of the IP children come from very weak economic backgrounds and are, therefore, out-of-school. These public provisions are supposed to be their intellectual lifelines.

\section{Literacy Through Libraries?}

The $21^{\text {st }}$ century kicked off with the noble vision for individuals to have acquired the necessary aptitudes for both qualitative and quantitative reading, incorporated skills to find, evaluate, and use information effectively, and, improved their knowledge management expertise (Ramirez 2002). Apparently, those concerned with the welfare of children growing in an increasingly information-driven environment acknowledges that a library is a significant point of access to information playing a key role in preparing children for the demands of the times. If it exists within a school setting or within a community, children coming from weak economic backgrounds are given an equal chance as their more privileged counterparts to reach their full potential and discover a road to learning for life. The stance adopted here is that a wide access to books and other learning resources translates to empowerment of children, and can equip them with better chances at competing.

Traditionally, the libraries have been widely acknowledged for its contribution to the development of literacy. Through its collection, which are objective sources of information, and ultimately through reading, which it fosters, libraries can contribute to the children's leisure needs as well as their intellectual, emotional, social and educational development (Elkin, J.C., 1995). It is, inarguably, where most of love for learning is given birth to. Those one in the belief that libraries exist "to give meaning to the continuing human attempt to transcend time and space in the advancement of knowledge and the preservation of culture." are the ones who rise above current situations and build libraries, motivated primarily by the philosophy that everyone should have a continuing access to the information resources necessary for coping with 
the complexity of the ever-changing environment. (Crawford W. \& Gorman, M., 1995, p. 3)

Libraries are also a major socializing factor, other than the home and the school. It is a very basic provision that needs to be present within the school and community setting, more so now than ever before when talks about social inclusion abound in the information arena.

Libraries are vital infrastructures in the education of children, a very valuable resource, a place to learn and socialize and provides the most promising context for the true collaboration between and among the various professional providers to come to fruition. (Klein 1994).

Trevor Dickinson (1990), in his article The Need for Story, affirmed the importance of reading, public and school libraries when he wrote that:

Some things stay the same because they are rooted in the deepest fabric of our society. One of these constancies is the need for story, story told and, more recently, story read...They need to be surrounded by rich print worlds - which place special obligations upon school and public libraries. They share a particular responsibility to demonstrate, through their book provision, that the adult world deeply cherishes children. That essential demonstration pays dividends in helping the growing children into adults who, touched from their earliest years by the sad and joyful magic of books, have been given the chance to be creative, imaginative beings, more fully conscious of, and more sensitive to, the needs of the many living worlds about them...in presenting the children with the best, most considered of language in the best of books, teachers and librarians are enabling them to possess a music of speech, giving them all an improved chance of something to day, and the means by which to say it for themselves. (p. 38)

A library serves several roles within the school setting: It is (1) a materials and technology center; (2) an information resource with an information intermediary; and (3) a teaching and learning environment. It cannot be argued, therefore, that institutions charged with the development and welfare of children, should guarantee that this basic provision exists within the school setting for the benefit of the schoolchildren, and public libraries have to be a priority as well so that the underprivileged children coming from very weak economic backgrounds who are not in school may be given an equal opportunity to improve their lots.

It is sad that despite all that has been written about the importance of access to information resources through libraries, not much have been done to improve current conditions primarily because the fiscal constraint itself has crippled the desire to build libraries, and librarians who should be the first to take up the cudgels for libraries are also discouraged to pursue what seems like an impossible dream.

This culture of resignation which has plagued the country for sometime now is not only crippling but is also mediocrity-friendly, as the earlier figures on academic performance and the dismal state of public and public elementary school libraries in the country can attest. Poor fiscal allocation is a reality to contend with but it should never rationalize acquiescing to the status quo. 


\section{Conclusion}

Coalitions are crucial in empowering children with the knowledge and skills not only to survive but also to thrive in a world driven more and more by information (Loomis 1990). The setting up of school and public libraries should be taken no longer as hopeless pursuits but more as urgent challenges especially as the other libraries the world over unmask new faces and metamorphose with technology. While we should strive to be one with the rest of the world in the rush to join the digital marathon, it should not be at the expense of scores of underprivileged children who are part of our collective social responsibility. And so, no matter how complex, or how unfashionable, to be advocating for libraries in the now wired-world, it is fitting to remember that as a country we have uniqueness of our own, and part of such uniqueness are our information needs which currently border on both extreme poles of the traditional and the advanced, with the former occupying the larger slice of the pie. How does a nation, with most of its population still information resource-hungry, and barely out struggling still to patch the divide at the national level, catch up with yet another bigger challenge that threatens to widen this gap even more, and compete with its already overburdened and problematic fiscal situation? The question of which to prioritize becomes crucial.

Southern Mindanao realities should dictate the course of action its major stakeholders are supposed to take towards the advancement of the welfare of its children. That would be the first and foremost step!

\section{References}

Abad, Florencio (2004). Schools are first: Empowering schools to improve Philippine education. (Speech at the National Educators Congress, Bacolod Convention Plaza Hotel, Bacolod City, 18 October 2004)

Dickinson, T. (1990). The need for story. Books for Keeps, no. 64,

Elkin, J.C. (1990) The role of children's libraries. In Elkin, J.C. Focus on the child: Libraries, literacy and learning. London: Library Association.

Gorman, W. \& Gorman, M. (1995). Future libraries: Dreams, madness \& reality. Chicago: American Library Association.

Hornberger, N.H. (Ed.) (1997). Indigenous literacies in the Americas: Language planning from the bottom up. Berlin: Mouton de Gruyter.

Klein, S. (1994). Young children: intervention and education. In L.L. Walling \& M.M. Irwin (Eds.) Information services for people with developmental disabilities: The library manager's handbook. Westport, Conn.: Greenwood Press.

Loomis, A. (1990). Building coalitions for information literacy. Columbia, S.C.: Carolina Library Association, Inc.

Megatrends: The future of the Filipino child (1998). Manila: Katha Publishing Co. 
National Center for Education Statistics (2003). TIMMS 2003 Results. Retrieved February 27, 2005, from http://nces.ed.gov/timms/Results03.asp

National Economic and Development Authority (2004). Inventory in education and training. Medium-term Philippine Development Plan, 2001-2004. Retrieved March 13, 2005, from http://www.neda.gov.ph/mtpdp/chapters 1015/ch10.htm

Office of Arts and Libraries (1984). School libraries: The foundations of the curriculum. (Report of the Library and Information Services Council's Working Party on School Library Services)

Ramirez, E. (2002). Reading, information literacy, and information culture.. Retrieved December 15, 2004 , from http://www.nclis.gov/libinter/infolitconf\&meet/papers/ramirez-fullpaper.pdf

\section{Authors’ Notes}

Fraulein Agcambot OCLARIT represents South Central Mindanao as National Board of Trustee of the Philippine Librarians Association, Inc. (PLAI) and is incumbent Board Secretary of the SOCCSKSARGEN Librarians Association (SOCOLA). She is the Chief Librarian of the Valdez Mother and Child (VMC) City College in Tacurong City, Sultan Kudarat Province and a Part-Time Faculty of Library and Information Science at the Notre Dame of Marbel University, City of Koronadal, South Cotabato.

Ivan Limbungan ORTUOSTE is a Faculty of the College of Liberal Arts of the Notre Dame of Marbel University in Koronadal City, South Cotabato. He is currently finishing his M.A. in Sociology at the Ateneo de Cagayan - Xavier University, Cagayan de Oro City, Philippines. 
Reproduced with permission of the copyright owner. Further reproduction prohibited without permission. 